\title{
Transcriptional analysis of differential carbohydrate utilization by Clostridium acetobutylicum
}

\author{
Correspondence \\ Christian J. Sund \\ christian.sund@us.army.mil
}

Received 14 December 2009

Revised 12 July 2010

Accepted 22 July 2010

\author{
Matthew D. Servinsky, James T. Kiel, Nicole F. Dupuy \\ and Christian J. Sund
}

U S Army Research Laboratory, 2800 Powder Mill Road, Adelphi, Maryland 20783, USA

\section{INTRODUCTION}

Clostridium acetobutylicum is a low-GC, Gram-positive, spore-forming anaerobe that was used in industrial fermentations to produce organic solvents by a process known as ABE (acetone, butanol, ethanol) fermentation in the early twentieth century (Jones \& Woods, 1986). The use of ABE fermentation diminished as the chemical synthesis of these products became more economically favourable. The search for renewable fuel sources and the depletion of oil reserves have revived interest in $\mathrm{ABE}$ fermentation as a source of alternative fuels (Gapes, 2000). Successful utilization of $C$. acetobutylicum in industry will require a detailed understanding of its genetics and physiology, which will facilitate strain development and the optimization of fermentation conditions (Behrens et al., 2001).

Abbreviations: ABC, ATP-binding cassette; ABE, acetone, butanol, ethanol; CCR, carbon catabolite repression; CGM, clostridial growth medium; CRE, catabolite-responsive element; GntP, gluconate : $\mathrm{H}^{+} ; \mathrm{GPH}$, glycoside-pentoside-hexuronide; MFS, major facilitator superfamily; PPP, pentose phosphate pathway; PTS, phosphotransferase system.

The GEO series accession number for the microarray data associated with this study is GSE18471.

Two supplementary figures and two supplementary tables are available with the online version of this paper.
An advantageous characteristic of C. acetobutylicum is its ability to grow on a variety of carbohydrates, making the fermentation of many agricultural, industrial and waste products possible (Ezeji \& Blaschek, 2008; Qureshi et al., 2006). Fermentation of materials composed of carbohydrate mixtures will inevitably depend on the regulatory response of the organism to carbohydrate and nutrient availability. Therefore, in-depth knowledge of the organism's capacity to respond to, take up and assimilate various carbohydrates is essential for increasing the efficiency of ABE fermentation of carbohydrate mixtures.

Many bacteria have evolved mechanisms that enable the selective uptake and catabolism of carbohydrates that allow the most rapid growth, providing a competitive advantage over other organisms (Brückner \& Titgemeyer, 2002; Saier et al., 1996; Singh et al., 2008). For the majority of heterotrophic bacteria glucose is the preferred, or primary, carbon source. In the presence of glucose, the transcription of genes required for the utilization of secondary carbon sources is repressed and pre-existing enzymes are often inactivated to maximize the utilization of the preferred carbohydrate, despite the presence of secondary carbohydrates (Brückner \& Titgemeyer, 2002; Singh et al., 2008). This phenomenon is referred to as carbon catabolite 
repression (CCR) and is a conserved form of regulation in clostridia (Brückner \& Titgemeyer, 2002; Saier et al., 1996; Tangney et al., 2003). Previous studies have identified several catabolic operons in $C$. acetobutylicum that are regulated in response to the carbohydrates present in the growth medium (Behrens et al., 2001; Rodionov et al., 2001; Tangney et al., 2001, 2003; Yu et al., 2007). Also, the catabolite control protein CcpA and catabolite-responsive elements (CREs) for many operons have been tentatively identified in the organism (Behrens et al., 2001; Brückner \& Titgemeyer, 2002; Rodionov et al., 2001; Tangney et al., 2003). A more detailed understanding of CCR in this bacterium will require analysis of the regulation of all operons potentially controlled by CCR.

The majority of the catabolite-responsive genes are likely to be those which encode specific metabolic enzymes or transport systems. C. acetobutylicum is able to ferment a wide variety of carbohydrates and thus encodes a diverse set of metabolic enzymes (Nölling et al., 2001). Previous studies have described the genes for the pentose phosphate pathway (PPP) and some putative regulatory elements (Kanehisa et al., 2006; Karp et al., 2005; Rodionov et al., 2001). Genes for two pathways for galactose metabolism, the Leloir pathway and the tagatose-6-P pathway, are present in $C$. acetobutylicum and are located within one region of the genome (Gutierrez \& Maddox, 1996; Nölling et al., 2001; Yu et al., 2007). Multiple genes encoding putative regulatory proteins are located in or near operons for the PPP, the Leloir pathway and the tagatose-6-P pathway, indicating that regulation of these pathways may be multifactorial (Nölling et al., 2001; Rodionov et al., 2001; Yu et al., 2007). Potential CRE, AraR and XylR consensus sequences have been identified, but further experiments need to be performed to confirm these predictions and fully elucidate the regulatory processes (Rodionov et al., 2001).

Three types of transporters have been identified that are involved in sugar uptake in C. acetobutylicum (Nölling et al., 2001). PTSs are the most prevalent uptake mechanism for sugars in solventogenic bacteria and some are induced in a substrate-specific manner in C. acetobutylicum (Behrens et al., 2001; Mitchell \& Tangney, 2005; Tangney et al., 2001, 2003; Tangney \& Mitchell, 2007; Yu et al., 2007). Analysis of the $C$. acetobutylicum genome using bioinformatics has identified 13 putative PTS EII enzymes (Nölling et al., 2001; Mitchell \& Tangney, 2005). The clostridial PTS catalyses the specific binding of substrate, its transfer across the cell membrane and concomitant carbohydrate phosphorylation (Mitchell et al., 1991; Reid et al., 1999; Tangney et al., 1998a, b; Tangney \& Mitchell, 2000). The similarity of the $C$. acetobutylicum PTS to PTSs found in other well-characterized bacteria, particularly other low-GC Gram-positive bacteria, has led to the suggestion that they may also play a role in CCR (Behrens et al., 2001; Saier \& Reizer, 1992; Singh et al., 2008; Tangney et al., 2003).

The remaining two types of sugar transport systems in $C$. acetobutylicum do not phosphorylate their carbohydrate substrates during the transport process. One is the typical binding-lipoprotein-dependent transport system of $\mathrm{ABC}$ transporters found in Gram-positive bacteria (Saurin \& Dassa, 1994; Tam \& Saier, 1993). The system utilizes ATP for energy; however, sugar molecules are not phosphorylated concomitantly with transport. C. acetobutylicum also uses ionic-gradient-driven transporters, including members of both families within the major facilitator superfamily (MFS), the gluconate: $\mathrm{H}^{+}$(GntP) and glycosidepentoside-hexuronide (GPH) families (Nölling et al., 2001). Many members of the GPH family of MFS transporters are regulated by the PTS by either phosphorylation or direct interaction (Deutscher et al., 2006; Poolman et al., 1996).

Annotation of the C. acetobutylicum genome sequence identified multiple metabolic pathways for carbohydrate catabolism and potential PTS-, ABC-, GPH- and GntP-type transporters (Nölling et al., 2001). Further bioinformatics and Northern blot analysis were used to confirm sugarspecific gene expression for a few of the PTSs (Behrens et al., 2001; Tangney \& Mitchell, 2000, 2007; Tangney et al., 2001; $\mathrm{Yu}$ et al., 2007). In this study we analysed the differential transcription profiles of $C$. acetobutylicum grown with eleven different sugars as the primary carbon source: glucose, mannose, galactose, fructose, arabinose, xylose, sucrose, lactose, maltose, cellobiose and starch. This genome-wide gene expression analysis suggests a sugar specificity in multiple transport systems and metabolic enzymes.

\section{METHODS}

Bacterial strain growth. C. acetobutylicum ATCC 824 was purchased from the American Type Culture Collection (ATCC) and used in all experiments. Stock cultures were maintained as suspensions in $30 \%$ glycerol stored at $-80{ }^{\circ} \mathrm{C}$. Cultures were grown in anaerobic conditions at $35{ }^{\circ} \mathrm{C}$ with an atmosphere of $5 \% \mathrm{CO}_{2}, 5 \% \mathrm{H}_{2}$ and $90 \% \mathrm{~N}_{2}$ inside a Bactron I Anaerobic Chamber (Shell Laboratories). Spore suspensions were heat shocked for $10 \mathrm{~min}$ at $80{ }^{\circ} \mathrm{C}$ prior to the inoculation of starter cultures, which were grown for approximately $24 \mathrm{~h}$ at $35^{\circ} \mathrm{C}$ in clostridial growth medium (CGM) containing the following per litre of distilled water: $\mathrm{KH}_{2} \mathrm{PO}_{4}, 0.75 \mathrm{~g}$; $\mathrm{K}_{2} \mathrm{HPO}_{4}, 0.75 \mathrm{~g}$; $\mathrm{MgSO}_{4} \cdot \mathrm{H}_{2} \mathrm{O}, 0.4 \mathrm{~g} ; \mathrm{MnSO}_{4} \cdot \mathrm{H}_{2} \mathrm{O}, 0.01 \mathrm{~g} ; \mathrm{FeSO}_{4} .7 \mathrm{H}_{2} \mathrm{O}, 0.01 \mathrm{~g} ; \mathrm{NaCl}$, $1.0 \mathrm{~g}$; asparagine, $2.0 \mathrm{~g}$; yeast extract, $5.0 \mathrm{~g}$; $\left(\mathrm{NH}_{4}\right)_{2} \mathrm{SO}_{4}, 2.0 \mathrm{~g}$; and carbohydrate, $5 \mathrm{~g}$ (Wiesenborn et al., 1988). The media were rendered anaerobic by vented overnight incubation in the anaerobic chamber. After overnight growth in glucose-containing medium, cells were isolated by centrifugation then washed twice with and resuspended in CGM lacking a carbohydrate, to the original starting volume. Subcultures were started in CGM containing different carbohydrates by making 1:30 dilutions of the washed cells in fresh CGM supplemented with $0.5 \%$ of one of the following carbon sources: glucose, mannose, galactose, fructose, arabinose, xylose, sucrose, lactose, maltose, cellobiose or starch. The subcultures were grown for approximately $14 \mathrm{~h}$ and then diluted $1: 10$ into fresh CGM containing $0.5 \%$ of the corresponding carbon source for each experimental culture to be used for RNA isolation.

RNA isolation. Cultures were grown to $\mathrm{OD}_{600}$ (Varian Cary 1G) 0.20.25 , at which point the cultures were treated with rifampicin, chloramphenicol and phenylmethanesulfonyl fluoride (PMSF) at final concentrations of $30 \mu \mathrm{g} \mathrm{ml}^{-1}, 50 \mu \mathrm{g} \mathrm{ml}^{-1}$ and $0.5 \mathrm{mM}$, respectively. 
Cultures were immediately placed in an ice-water bath for $15 \mathrm{~min}$, after which $7.5 \mathrm{ml}$ volumes were centrifuged in sealed tubes at $5000 \mathrm{~g}$ for $10 \mathrm{~min}$ at $4{ }^{\circ} \mathrm{C}$. The supernatant was decanted and the cell pellets were resuspended in $750 \mu \mathrm{l}$ of a solution containing a $2: 1$ ratio of RNA Protect (Qiagen) to PBS. After $5 \mathrm{~min}$ incubation at room temperature the cell suspensions were pelleted by centrifugation and stored at $-80{ }^{\circ} \mathrm{C}$. The cell pellets were thawed on ice and the cells were resuspended in $1.5 \mathrm{ml}$ RLT buffer (Invitrogen) supplemented with $15 \mu \mathrm{l} \beta$-mercaptoethanol and homogenized with $0.1 \mathrm{~mm}$ diameter zirconia/silica beads (BioSpec) in a Mini-Beadbeater-16 (BioSpec) for $4 \mathrm{~min}$. Total RNA was extracted from homogenized cells using an RNeasy mini kit (Qiagen) according to the manufacturer's instructions.

Real-time PCR. RNA was treated with DNase I (Qiagen) on the RNeasy columns according to the manufacturer's instructions. After elution, the RNA was treated with a Turbo DNA-free kit (Applied Biosystems) using the rigorous DNase treatment protocol supplied by the maufacturer. The RNA was tested for DNA contamination using real-time PCR with primers for NAD(FAD)-dependent dehydrogenase (CAC0905). First-strand cDNA was synthesized from $140 \mathrm{ng}$ total RNA using a Superscript II kit (Invitrogen) as per the manufacturer's instructions. Real-time PCR primers were designed (see Supplementary Table. S1, available with the online version of this paper) using Primer3 software to amplify products that were between 125 and $130 \mathrm{bp}$ in size (Rosen \& Skaletsky, 2000). Each real-time PCR contained $12.5 \mu \mathrm{l}$ iQ SYBR Green Supermix (Bio-Rad), $200 \mathrm{nM}$ of each primer, $1 \mu \mathrm{l}$ DNA template and a sufficient volume of water to bring the final reaction volume to $25 \mu$ l. Real-time PCR was performed in a Smart Cycler 2 (Cepheid) using the following programme: $95{ }^{\circ} \mathrm{C}$ for $3 \mathrm{~min}$ (1 cycle) then $95{ }^{\circ} \mathrm{C}$ for $10 \mathrm{~s}, 54{ }^{\circ} \mathrm{C}$ for $15 \mathrm{~s}$ and $72{ }^{\circ} \mathrm{C}$ for $15 \mathrm{~s}$ (45 cycles). Fluorescence data were collected during the extension step and melting-curve analysis was performed following amplification to ensure that a single product was formed. The PCR efficiency for each primer set was determined by analysing three replicates of tenfold serial dilutions of BamHI-digested chromosomal DNA. To determine relative expression levels, $1: 200$ dilutions of cDNA were analysed as described by Pfaffl (2001) using CAC0905 as an internal standard. This gene was selected to be the control as it had consistent expression levels (based on microarray data) in all of the conditions tested.

Microarray hybridization and analysis. RNA for microarray analysis was concentrated by 2-propanol precipitation followed by rehydration in water to obtain an RNA concentration of at least $1 \mu \mathrm{g} \mu \mathrm{l}^{-1}$. The quantity and integrity of the RNA were determined using an Agilent Bioanalyser (Agilent Technologies). Synthesis of Cy3-labelled double-stranded cDNA (ds-cDNA) and hybridization to DNA microarrays was performed essentially as described by the NimbleGen Arrays User's Guide for Gene Expression Analysis (Roche NimbleGen). ds-cDNA was synthesized from $10 \mu \mathrm{g}$ random-hexamer-primed total RNA using a Superscript Double-Stranded cDNA Synthesis kit (Invitrogen). RNA was then removed by incubating samples with $2 \mathrm{ng}^{-1} \mathrm{l}^{-1}$ (final concentration) of RNase A (Promega) at $37{ }^{\circ} \mathrm{C}$ for $10 \mathrm{~min}$. The ds-cDNA was purified using a phenol/ chlorform extraction followed by ethanol precipitation. The resulting ds-cDNA pellet was dissolved in $20 \mu \mathrm{l}$ water and the quality of dscDNA was determined by analysis in an Agilent Bioanalyser (Agilent Technologies). Samples were only used if they had a concentration $\geqslant 100 \mathrm{ng} \mathrm{l}^{-1}$, an $A_{260} / A_{280}$ ratio $\geqslant 1.8$, and a median size $\geqslant 400 \mathrm{bp}$. For each sample, $1 \mu \mathrm{g}$ ds-cDNA, $40 \mu \mathrm{l}$ Cy3-labelled nonamers (TriLink Biotechnologies) (diluted to a concentration of $20 \mu \mathrm{g}$ per $42 \mu \mathrm{l}$ of $125 \mathrm{mM}$ Tris $\mathrm{pH} 7.4,12.5 \mathrm{mM} \mathrm{MgCl}_{2}, 1.75 \mu \mathrm{ml}^{-1} \beta$ mercaptoethanol) and sufficient water to bring the reaction volume to $80 \mu \mathrm{l}$ was incubated at $98{ }^{\circ} \mathrm{C}$ for $10 \mathrm{~min}$ and then cooled in an icewater bath for $10 \mathrm{~min}$. Ten microlitres of dNTPs (Invitrogen) (10 mM dATP, $10 \mathrm{mM}$ dGTP, $10 \mathrm{mM}$ dTTP, $10 \mathrm{mM}$ dCTP in $1 \mathrm{M}$

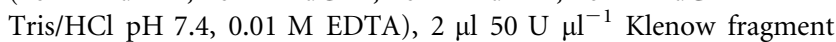

(New England Biolabs) and $8 \mu \mathrm{l}$ water were added to each reaction. After incubation at $37{ }^{\circ} \mathrm{C}$ in the dark for $2 \mathrm{~h}$, the reactions were stopped by the addition of $10 \mu \mathrm{l} 0.5 \mathrm{M}$ EDTA, and the Cy3-labelled ds-cDNA was precipitated by the addition of $11.5 \mu \mathrm{l} 5 \mathrm{M} \mathrm{NaCl}$ and $121.5 \mu \mathrm{l}$ 2-propanol and incubation at room temperature in the dark for $10 \mathrm{~min}$. The samples were centrifuged at $12000 \mathrm{~g}$ for $10 \mathrm{~min}$ at room temperature and the supernatant was removed. The resulting pellets were washed with $500 \mu \mathrm{l}$ ice-cold $80 \%$ ethanol, dried and then rehydrated in $25 \mu \mathrm{l}$ water. Two-microgram samples of Cy3-labelled ds-cDNAs were transferred to new tubes, dried in a SpeedVac (Eppendorf) and rehydrated in $3.3 \mu \mathrm{l}$ Sample Tracking Control solution (Roche NimbleGen). Then $8.7 \mu$ l hybridization solution containing $6 \mu \mathrm{l} 2 \times$ Hybridization Buffer, $2.4 \mu \mathrm{l}$ Hybridization Component A and $0.3 \mu \mathrm{l}$ Alignmet Oligo (Roche NimbleGen) were added to each tube. Eight microlitres of each Cy3-labelled ds-cDNA solution was transferred to a separate port of a 4-plex Mixer, which was previously adhered to a 4-plex one-colour gene expression array (Roche NimbleGen) designed for C. acetobutylicum. Each quadrant of the array contained two replicates of nine perfect-match probes, approximately $60 \mathrm{bp}$ in length, for each of the 3842 open reading frames annotated in the C. acetobutylicum genome. Control probes were also present to ensure that there was no inter-quadrant contamination during the hybridization process. The arrays were hybridized at $42{ }^{\circ} \mathrm{C}$ for $16 \mathrm{~h}$ in a NimbleGen Hybridization System 4 (Roche NimbleGen) using mix mode B. Following removal of the hybridization chambers, the microarray slides were washed using a NimbleGen Wash Buffer kit according to the manufacturer's instructions. The arrays were imaged with an Agilent Microarray Scanner at $532 \mathrm{~nm}$ and $2 \mu \mathrm{m}$ resolution. NimbleScan software (Roche NimbleGen) was used to separate the composite images into four individual images corresponding to each hybridization area, align mapping grids and extract probe signal intensities. A sample-tracking control analysis was performed using NimbleScan software to ensure that there was no inter-well contamination during the hybridization process. NimbleScan software was used to normalize the data using quantile normalization, and gene calls were generated using Robust Multichip Averaging (RMA) (Bolstad et al., 2003; Irizarry et al., 2003). The $\log _{2}$-transformed RMA data files were imported into Arraystar 2.0 software (DNASTAR) and the mean expression levels of three arrays (one for each biological replicate) for each condition were considered. For comparisons between sugars, statistical significance was determined with a Bonferonni corrected moderated $t$-test and only genes that had a threefold or greater change in gene expression at $99 \%$ confidence were considered as significant (Smyth, 2004). All microarray data associated with this publication are available at the Gene Expression Omnibus (http://www.ncbi.nlm.nih.gov/geo/) and can be accessed with the series accession number GSE18471.

\section{RESULTS AND DISCUSSION}

One-colour DNA microarrays were used to determine gene expression levels of $C$. acetobutylicum grown to early exponential phase on eleven different carbohydrates, glucose, mannose, galactose, fructose, arabinose, xylose, sucrose, lactose, maltose, cellobiose and starch. RNA extraction, cDNA production and labelling, as described in Methods, were performed independently on three separate cultures for each carbohydrate. Each independent sample was hybridized to one microarray, equating to one technical replicate for each biological sample and three biological replicates for each condition tested. Comparisons were made between each combination of carbohydrate pairs using Bonferonni corrected, moderated $t$-tests and only genes that had a threefold 
or greater change in expression with $99 \%$ confidence were considered as significant (Smyth, 2004). A compilation of the results of these comparisons is presented in Fig. 1; detailed gene lists are available in the supplementary material (Supplementary Table S2). Examination of the data indicated that there was a broad range of differential gene expression in comparisons between the sugars. The extremes range from the mannose/fructose comparison, with two differentially expressed genes, to the glucose/ lactose comparison, with 113 differentially expressed genes. This represents between $0.05 \%$ and $3 \%$ of the predicted open reading frames. Relative expression levels determined by quantitative real-time PCR analysis of a subset of genes agreed with the overall expression patterns seen in the microarray analysis; however, the magnitude of changes was greater in the real-time PCR comparisons, which is probably due to the greater dynamic range of the PCR assay (Supplementary Fig. S1). A detailed examination of the data indicated that the majority of the differentially expressed genes appeared to be either involved in carbohydrate transport and catabolism or part of a chromosomally located prophage.

\section{Glucose, maltose and starch metabolism}

Glucose, cellobiose, maltose and starch are metabolized in a similar manner since they are all composed of glucose and vary only in chain length or linkages. The primary differences in the metabolism of these sugars are in their transport mechanisms and the hydrolysis of their glycosidic bonds. Glucose is a preferred sugar for C. acetobutylicum and many of the genes required for its metabolism are likely to be constitutively expressed (Yu et al., 2007). Nevertheless, one gene encoding a glucose PTS IICBA (CAC0570) was induced by glucose, maltose and starch when compared to the other carbohydrates tested (Fig. 2). A second putative glucose PTS is encoded by two divergently transcribed genes, CAC1353 and CAC1354, which encode PTS IICB and PTS IIA components, respectively. Neither of these genes had significantly altered gene expression, demonstrating that C. acetobutylicum may encode two glucose transporters, one which is constitutively expressed and another which is induced by glucose. Another possibility for the lack of induction of CAC1353 and CAC1354 is that the gene products are responsible for importing a substrate not tested in this study.

Starch and maltose induced the expression of an operon containing genes for another putative PTS IICB, malP (CAC0532), and a maltose-6'-P glucosidase, malH (CAC0533), (Tangney et al., 2001; Thompson et al., 2004). It is probable that MalP transports and phosphorylates maltose while $\mathrm{MalH}$ hydrolyses the resulting maltose-6-P into glucose and glucose-6-P (Thompson et al., 2004). Examination of the C. acetobutylicum genome failed to identify a maltose-specific PTS IIA component and no expression of PTS IIA correlates with growth on maltose (Nölling et al., 2001). Experimental evidence suggests that a constitutively expressed IIA is responsible for maltose PTS transport (Tangney et al., 2001). It is also possible that a promiscuous IIA is used for maltose transport as has been demonstrated in Bacillus subtilis and

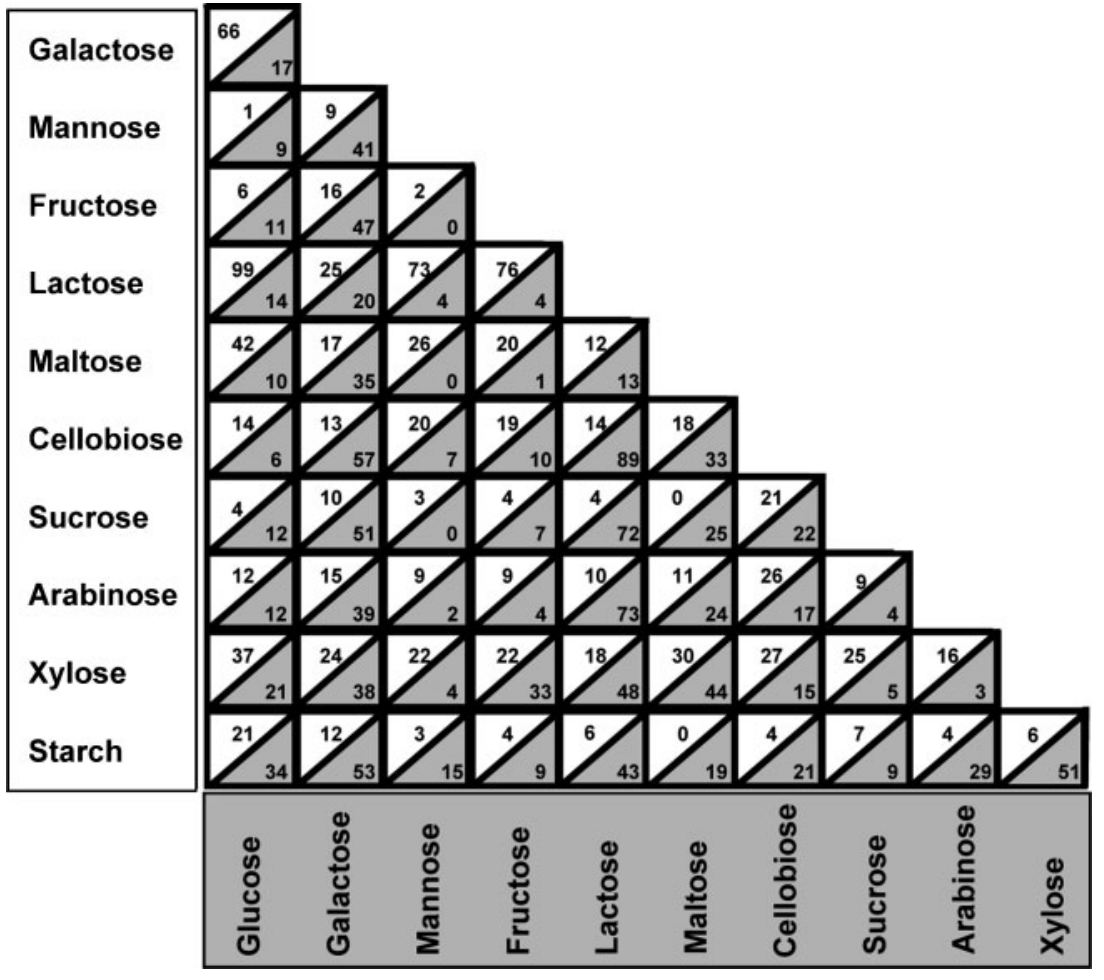

Fig. 1. Expression comparisons between each pair of carbohydrates. The upper left-hand corner of each square (white) indicates the number of statistically significant genes induced more than threefold by the carbohydrate on the $y$-axis when compared to the carbohydrate on the $x$-axis. The lower righthand portion of each square (grey) indicates the number of statistically significant genes induced more than threefold by the carbohydrate on the $x$-axis when compared to the carbohydrate on the $y$-axis. 
(a)

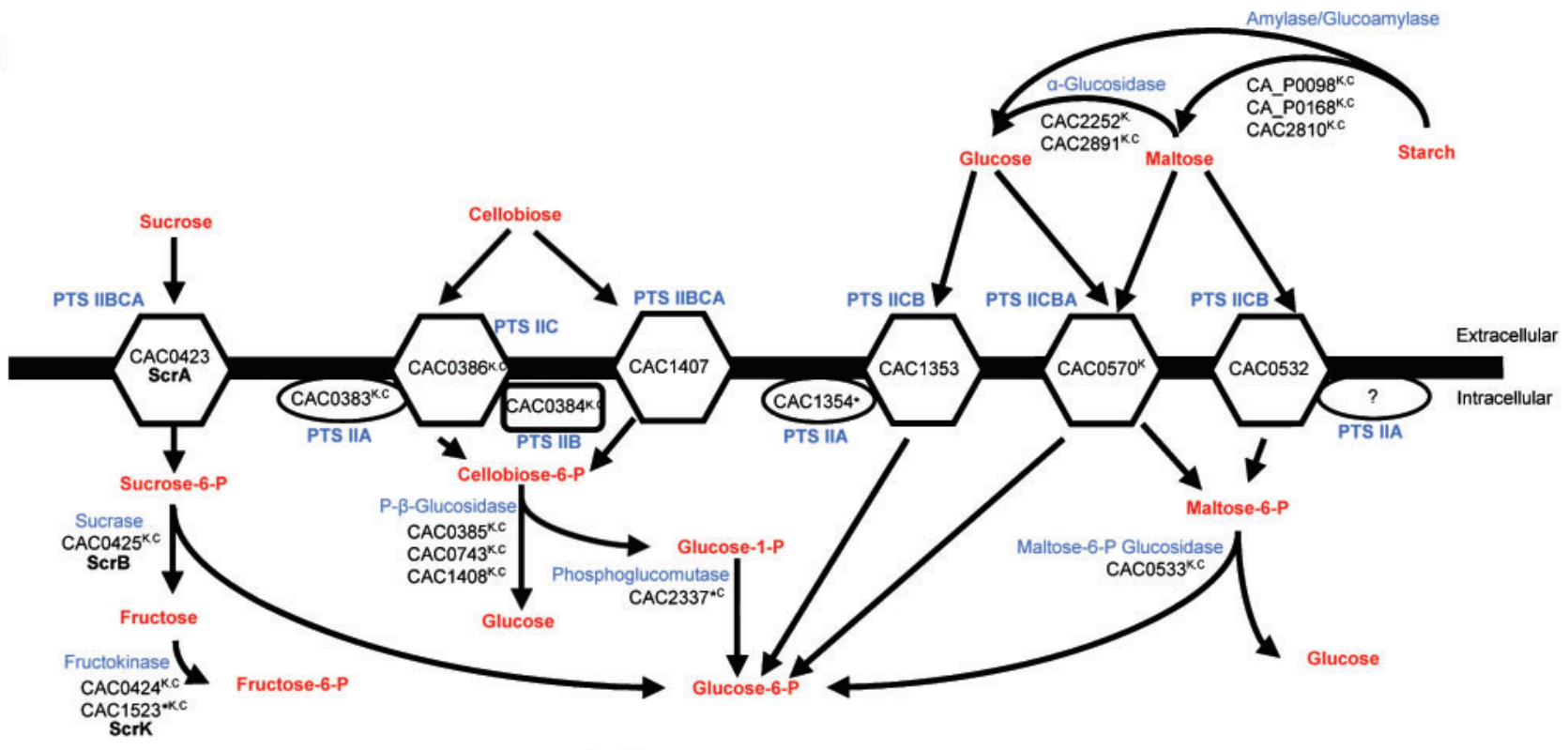

(b)

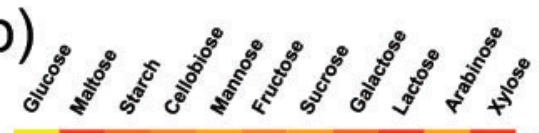

(c)
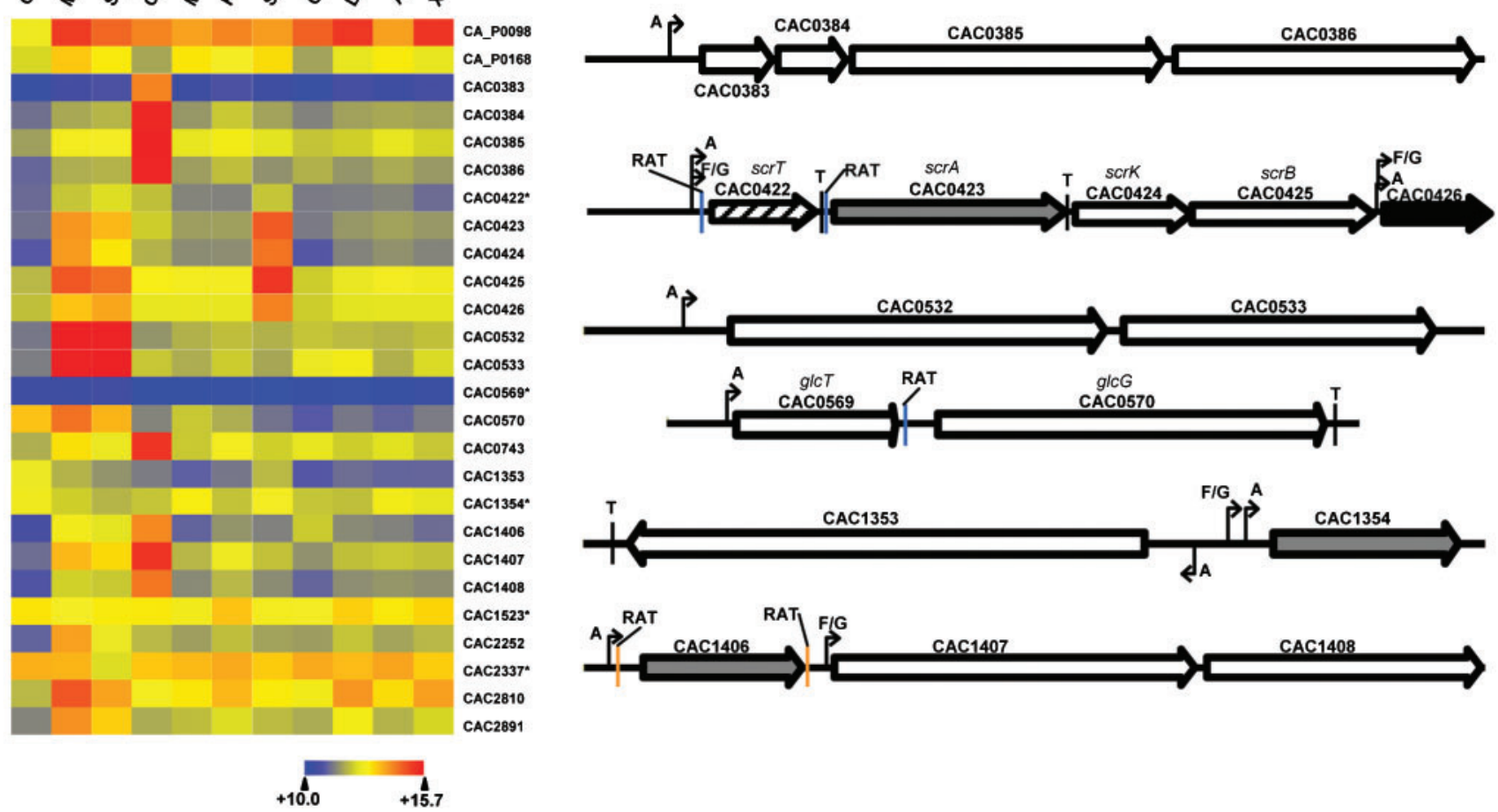

Fig. 2. Differential expression of sucrose, cellobiose, glucose, maltose and starch utilization genes. (a) Schematic of carbohydrate transport and utilization. Genes annotated in KEGG and BioCyc are identified by K and C, respectively. Genes that were not differentially expressed in any comparison between sugars are marked with an asterisk. (b) Heat map of log ${ }^{-}$ transformed expression values during growth on 11 different carbohydrates. A key indicating the range of $\log _{2}$-transformed expression values is located at the bottom of the heat map and gene names are listed on the right-hand side. Asterisks indicate genes that were not differentially expressed. (c) Genetic map of carbohydrate utilization operons. Transcriptional unit predictions made by Paredes et al. (2004) are identified as follows: genes that are part of the same transcriptional unit are similarly shaded, putative promoters are identified by bent arrows with letters indicating putative sigma factors and termination sites are marked by a vertical line with a T. Ribonucelotide antiterminator (RAT) sequences described by Tangney \& Mitchell $(2000,2007)$ are marked with vertical blue lines and RAT sequences identified in the current study are marked with vertical orange lines. 
Clostridium beijerinckii, in which the IIA component of the glucose PTS can also function as the sucrose IIA (Sutrina et al., 1990; Tangney \& Mitchell, 2000; Tangney et al., 1998a). Glucose PTS activity has been determined for $C$. acetobutylicum, and genes for three predicted glucose IIA components (CAC1354, CAC2995, CAC3427) were found to be constitutively expressed during growth on all sugars tested in this study (Tangney \& Mitchell, 2007). It is possible that one or all of these gene products could function in maltose transport.

It was not unexpected that the maltose PTS genes were induced by starch since the organism degrades starch into glucose, and smaller polysaccharides including maltose, by excreting an extracellular $\alpha$-amylase (Paquet et al., 1991). The gene encoding the $\alpha$-amylase (CA_P0168), which is found on the pSol megaplasmid and was characterized by Paquet et al. (1991), had significantly higher expression levels during growth on maltose as compared with cellobiose (Fig. 2), but there was no significant difference in any of the other comparisons. Increased expression of amylase in response to maltose is probably due to the cells' inability to sense starch itself, but rather only sense its amylolytic breakdown product maltose. A second pSol-located $\alpha$ amylase gene (CA_P0098) and a chromosomally located glucoamylase gene (CAC2810) had higher expression levels during growth on starch, maltose and lactose as compared with glucose. Additionally, maltose and starch induced two putative $\alpha$-glucosidase genes (CAC2252, CAC2891) when expression levels were compared to that caused by glucose induction. SignalP analysis of the protein sequences indicated that these two $\alpha$-glucosidases have Gram-positive secretion sequences and, therefore, can be predicted to hydrolyse the $\alpha$-1,4-glycosidic bonds of maltose in the extracellular matrix (Bendtsen et al., 2004). The RegPrecise database suggests that the two putative $\alpha$-glucosidase genes are regulated by the putative maltose regulator MalR, encoded by CAC0856 (Novichkov et al., 2010). The malR transcript was not differentially expressed in any of the comparisons done in this study.

\section{Cellobiose metabolism}

Cellobiose induced genes for two putative PTSs (Fig. 2). Genes for one PTS are located in an operon that encodes a PTS IIA (CAC0383), a PTS IIB (CAC0384), a P- $\beta$ glucosidase (CAC0385) and a PTS IIC (CAC0386). Expression of this operon was induced more than sixfold in cells grown on cellobiose when compared with cells grown on all other carbohydrates. Genes for a second potential cellobiose PTS are located in an operon encoding a $\beta$-glucosidase-specific PTS IIBCA (CAC1407) and a putative $\mathrm{P}$ - $\beta$-glucosidase (CAC1408). A gene encoding a potential BglG-type transcriptional regulator (CAC1406) is located upstream of CAC1407 in a monocistronic operon. Both of these operons were strongly induced by cellobiose, with expression levels ninefold greater than those induced by glucose. Starch and maltose also induced these genes compared with glucose, but to a lesser extent than cellobiose. The gene product of CAC1406 is a putative BglG-type transcriptional antiterminator, which may regulate expression of CAC1407 and CAC1408. Further evidence for this suggestion is that putative ribonucleotide antiterminator sequences similar to those described by Tangney \& Mitchell (2000) are located 114-84 and 153124 bases upstream of the translational start sites of CAC1406 and CAC1407, respectively (Fig. 2c). It is interesting to note that transcription of CAC1406 is regulated, since BglG antiterminators from other organisms are controlled via phosphorylation by the PTS (Amster-Choder \& Wright, 1997). This is also in contrast to other putative antiterminators in C. acetobutylicum, which were not differentially expressed at the mRNA level in this study. A third P- $\beta$-glucosidase gene (CAC0743) was induced in cells grown on cellobiose but not in cells grown on any other carbohydrates. These data show that $C$. acetobutylicum contains multiple cellobiose-inducible operons with functions connected to cellobiose metabolism. In total, genes for two PTSs and three P- $\beta$-glucosidases were found to be induced during growth on cellobiose; the resulting gene products would provide the cells with multiple mechanisms to import, phosphorylate and hydrolyse $\beta$-glucosides for entry into glycolysis.

\section{Sucrose metabolism}

Previous studies identified a sucrose metabolism operon (Tangney \& Mitchell, 2000), scrA/K/B, which encodes PTS IIBCA domains on a single gene (scrA, CAC0423), a fructokinase ( $s c r K$, CAC0424), and a sucrose-6-P hydrolase (scrB, CAC0425). This operon had higher expression when cells were grown on sucrose, starch and maltose, compared with the other carbohydrates used in this study (Fig. 2). Sucrose induction of this operon is consistent with previous data (Tangney \& Mitchell, 2000); however, this is believed to be the first demonstration of $s c r A / K / B$ induction by starch and maltose. Tangney \& Mitchell (2000) hypothesized that the expression of this operon is controlled by the putative transcriptional antiterminator encoded by the upstream gene scrT (CAC0422), and the identified RNA antiterminator sequences upstream of $s c r T$ and scrA. In this study, scrT was not found to be differentially expressed; however, this does not preclude a regulatory role in sucrose metabolism since BglG-type transcriptional regulators are controlled by phosphorylation by the PTS (Amster-Choder \& Wright, 1997). Interestingly, a downstream gene for a putative AraC-type regulator (CAC0426) had a similar expression pattern to CAC0423-CA0425, suggesting that the CAC0426 gene product also may play a role in regulation of sucrose metabolism.

\section{Fructose and mannose metabolism}

There was very little difference in gene expression when comparing between cells grown on glucose, mannose or 
fructose, indicating that fructose and mannose are among the preferred carbohydrates for C. acetobutylicum. This is probably due to the fact that once fructose and mannose have been imported via the PTS each sugar only requires one additional enzyme for entry into glycolysis. A fructose PTS is encoded by a polycistronic operon that encompasses CAC0231-CAC0234 and includes genes for a putative DeoR-type transcriptional regulator (CAC0231), a 1-phosphofructokinase (CAC0232), a PTS IIA (CAC0233) and a PTS IIBC (CAC0234). This operon had the highest expression levels in fructose-grown cells; however, induction was also seen in cells grown on maltose and mannose (Fig. 3). Since the operon encodes the only putative 1phosphofructokinase (CAC0232) in the genome, this suggests that the PTS encoded by CAC0233 and CAC0234 is the primary fructose transporter. Additionally, the DeoRtype regulator (CAC0231) may be involved in regulation of this operon.

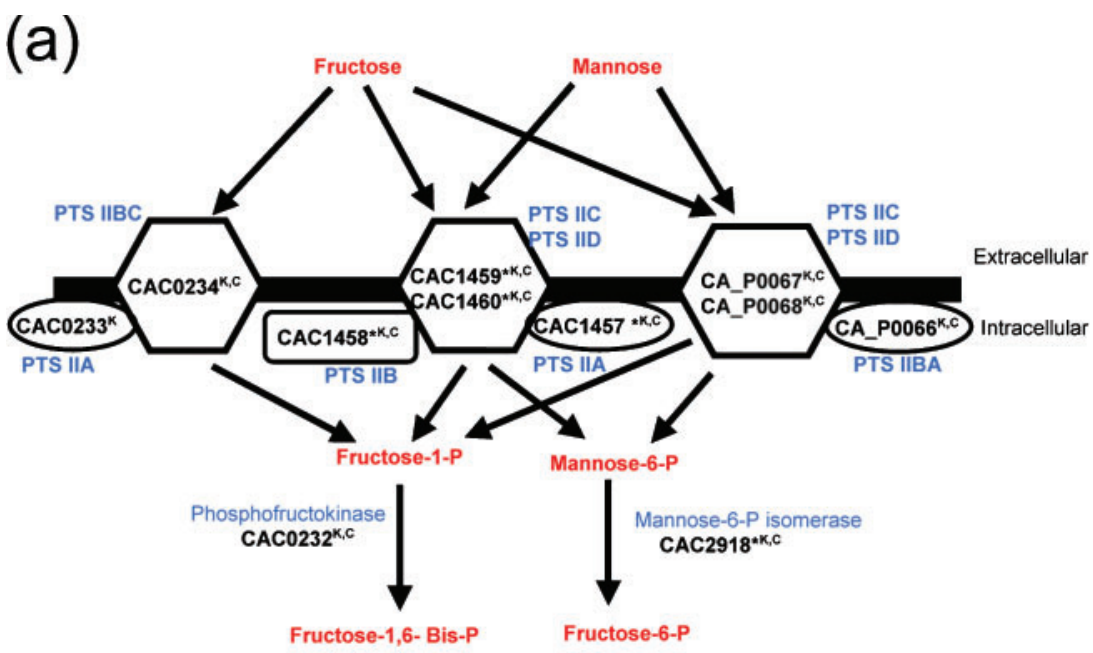

(b)

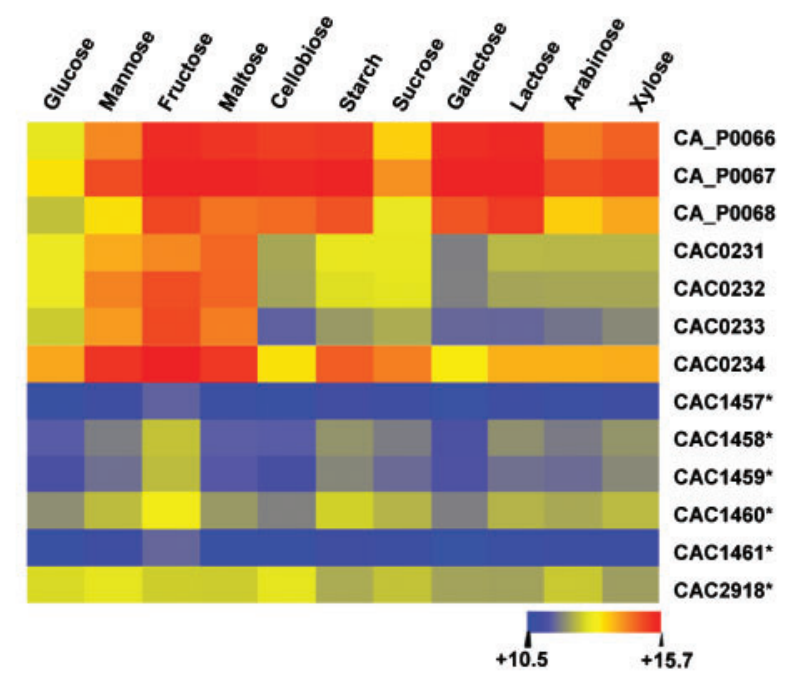

(c)

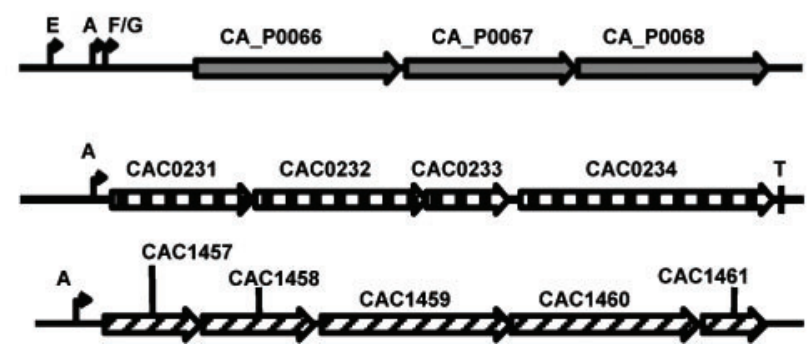

Fig. 3. Differential expression of fructose and mannose utilization genes. (a) Schematic of fructose and mannose transport and utilization. Genes are annotated as in Fig. 2a. (b) Heat map of $\log _{2}$-transformed expression values (as described in Fig. 2 legend). (c) Genetic map of fructose and mannose utilization operons. Transcriptional unit predictions made by Paredes et al. (2004) are identified as in Fig. 2c. 
There are genes for two PTSs in the genome that have high sequence homology to mannose/fructose PTSs in other organisms. Genes for one fructose/mannose PTS (CA P0066-CA_P0068) are located on the pSol megaplasmid and had higher expression levels during growth on starch, maltose, galactose, lactose, fructose and cellobiose compared with those on sucrose and glucose. Carbohydrate specificity for this PTS is difficult to establish based solely on expression data; however, the decreased expression levels in glucose-containing media suggest that this operon may be controlled via CCR. The second fructose/mannose PTS is encoded by CAC1457CAC1460 and did not show significant differences in expression levels in any condition that was tested. Perhaps this operon is constitutively expressed or is responsible for the transport of a carbohydrate that was not examined. A definitive mannose transporter could not be identified based upon expression data but it is likely that mannose as well as fructose is transported by one or both of the mannose/fructose PTSs. The gene encoding a putative mannose-6-P isomerase (CAC2918) was also not differentially expressed in any condition examined. This supports the notion that mannose is a preferred carbohydrate and, therefore, the genes required for its uptake and metabolism are constitutively expressed.

\section{Galactose and lactose metabolism}

The genes required for galactose and lactose utilization are clustered in one region of the genome inclusive of CAC2950 and CAC2966. This region consists of eight putative transcriptional units that encode regulatory proteins, PTSs and metabolic enzymes including enzymes for the Leloir pathway and the tagatose-6-P pathway for galactose metabolism (Reid, 2005). Induction of genes in this region was seen when cells were grown on galactose or lactose, with some genes having notably higher expression in galactose grown cells (Fig. 4).

Operons encoding putative PTSs for galactose and lactose transport are located in this region of the genome. The lactose PTS is encoded by two transcriptional units, CAC2964CAC2963 and CAC2966-CAC2965. The PTS IIB and IIC domains are encoded by one open reading frame, lacE (CAC2964), which is apparently co-transcribed with a gene for a 6-P- $\beta$-galactosidase, lacG (CAC2963). The PTS IIA component and a DeoR-type regulator are encoded by lacF (CAC2965) and lacR (CAC2966), respectively, and are located upstream of lacE (Yu et al., 2007). Genes for the putative galactose PTS are also situated on two operons. The PTS IIA (CAC2958) and IIB (CAC2957) components are encoded by one bicistronic operon and the gene for the PTS IIC (CAC2956) component is located on a separate monocistronic operon. Putative CRE sequences have been identified upstream of the operons encoding the galactose PTS and the operon encoding LacR, indicating that CcpA is likely to be involved in the regulation of these PTS systems (Rodionov et al., 2001).

Genes for the tagatose-6-P pathway are located on a single transcriptional unit (CAC2954-CAC2951). This operon putatively encodes a galactose-6-P isomerase (lacB, CAC2953; lacA, CAC2954), a tagatose-bisphosphate aldolase (gatY, CAC2952) and a tagatose-6-P kinase (lacC, CAC2951), and was highly expressed in lactose- and galactose-grown cells. A putative CRE sequence was identified upstream of the first gene of the operon, CAC2954, indicating that CcpA may be at least partially responsible for regulation of this operon. A monocistronic operon (CAC2955) encoding a putative DeoR-type regulator is located between the putative galactose PTS genes and the tagatose-6-phospate pathway operon. This gene was induced by both lactose and galactose, indicating another potential form of regulation for galactose and lactose metabolism.

A single operon (CAC2959-CAC2962) encodes the enzymes of the Leloir pathway and a putative LacI-type transcriptional regulator. The first three genes in this operon apparently encode the metabolic enzymes galactokinase (galK, CAC2959), UDP-galactose epimerase (galE, CAC2960) and galactose-1-P-uridylyltransferase (galT, CAC2961), with the final gene CAC2962 encoding the transcriptional regulator. Induction of this operon was seen during growth on galactose and lactose; however, expression levels induced by galactose were greater than those induced by lactose. This expression pattern differs from the other genes in this genomic region, indicating that the operon has a different mode of transcriptional regulation. Other genes (CAC0794, CAC1429, CAC2334, CAC2337) which appear to encode Leloir pathway enzymes are present elsewhere in the genome, but these genes were not differentially expressed in any of the conditions examined.

The operation of the Leloir pathway would suggest that galactose may be transported via a non-phosphorylating transport system, which is consistent with a previous report demonstrating that galactose transport is dependent upon the proton-motive force (Gutierrez \& Maddox, 1996). This suggests that a proton symporter may transport galactose; however, no specific transporter has been identified. Data presented here show that a gene for a putative symporter (CAC2835) was most highly expressed when cells were grown on galactose. This gene had high expression levels during growth on cellobiose, starch, maltose, lactose and xylose and decreased expression levels during growth on glucose, sucrose and mannose. This implies that CAC2835 is subject to CCR and that the gene product may transport galactose and/or other carbohydrates.

Lactose and galactose induced a putative arabinogalactan endo-1,4- $\beta$-galactosidase gene (CAC2570). This gene product has a putative export signal, as determined by SignalP, and therefore the enzyme is most likely to be present in the extracellular matrix (Bendtsen et al., 2004). The role of this enzyme would be to hydrolyse $\beta$-1,4-galactosidic linkages of type I arabinogalactans, releasing D-galactose and oligogalactans (Ryttersgaard et al., 2004). Presumably this enzyme is important for growth on hemicellulose since arabinogalactans are a major constituent of hemicellulose from plant cell walls. 


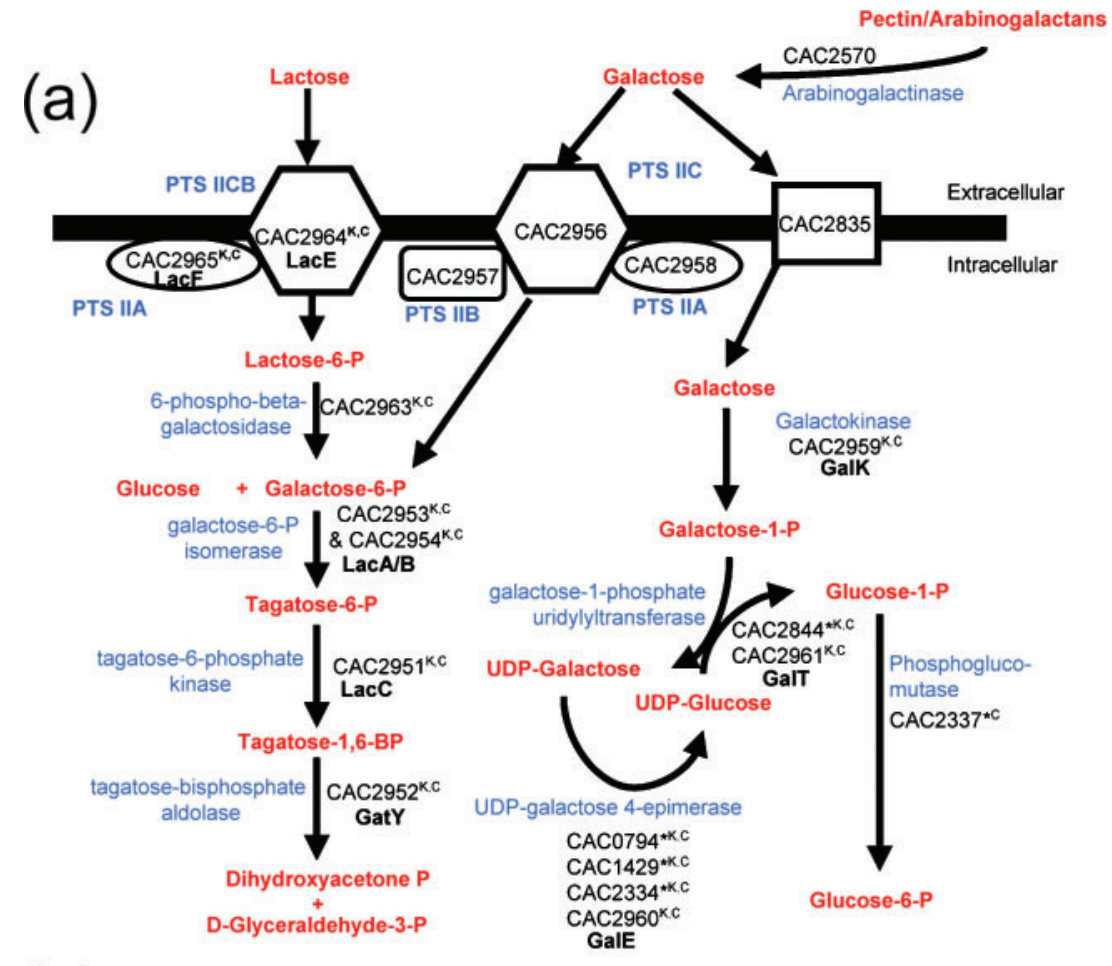

(b)

\section{Lactose \\ Galactose \\ Glucose}
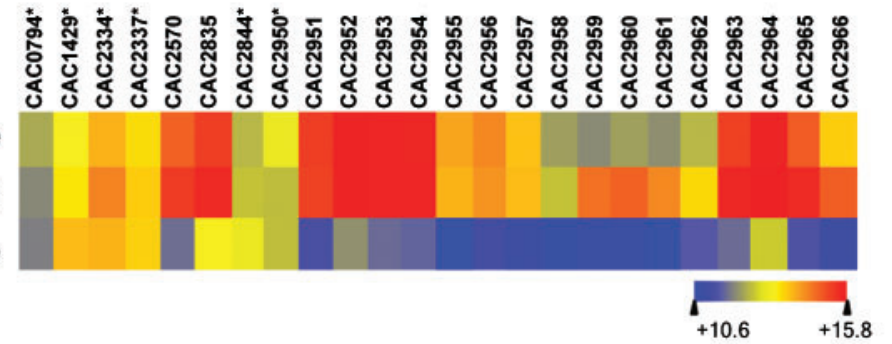

(C)

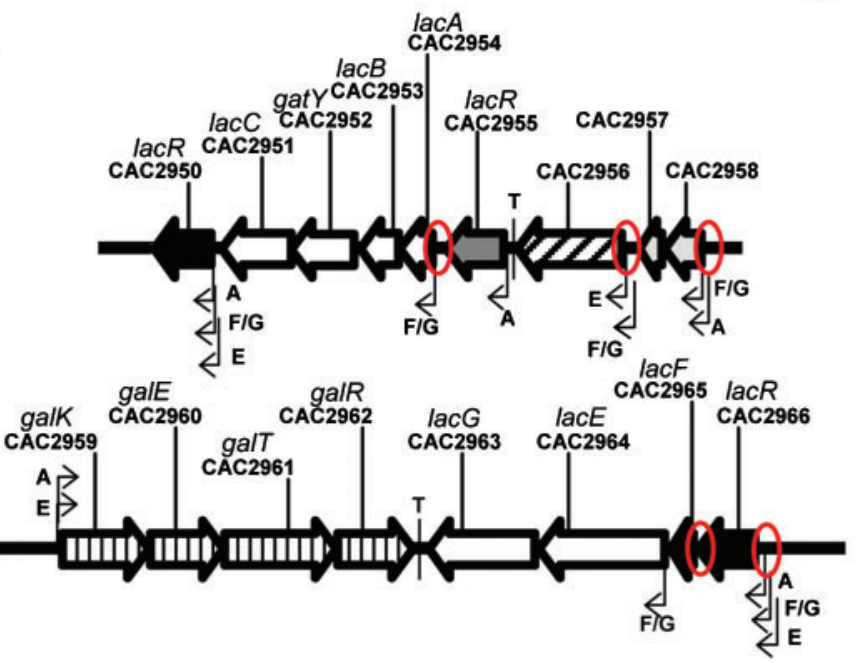

Fig. 4. Differential expression of galactose and lactose utilization genes. (a) Schematic of galactose and lactose transport and utilization. Genes are annotated as in Fig. 2a. (b) Heat map of $\log _{2}$-transformed expression values during growth on 11 different carbohydrates (as described in Fig. 2 legend). (c) Genetic map of galactose and lactose utilization operons. Potential CRE elements identified by Rodionov et al. (2001) are marked with red ovals. Transcriptional unit predictions made by Paredes et al. (2004) are identified as in Fig. 2c.

Data presented here indicate that the regulation of galactose and lactose metabolism in C. acetobutylicum is complex. Some genes were induced to similar levels by growth on galactose and lactose, while others were induced primarily by galactose. Both lactose and galactose induced genes encoding tagatose-6-P pathway enzymes for metabolizing
galactose-6-P. This would arise from the PTS transport of galactose or the PTS transport of lactose followed by the hydrolysis of lactose-6-P by a P- $\beta$-galactosidase. Genes encoding two PTSs, one for galactose and the other for lactose, had a similar regulatory pattern to the tagatose-6-P pathway genes. It is therefore likely that these operons are 
controlled by similar regulatory mechanisms that may involve one or both of the putative LacR regulators encoded by CAC2955 and CAC2966. These genes displayed similar expression patterns and are located upstream of the tagatose-6-P pathway operon and the lactose PTS operon, for CAC2955 and CAC2966, respectively. A gene for a third DeoR-type regulator, CAC2950, is located downstream of the tagatose-6-P pathway genes; however, this gene was not differentially expressed in any of the conditions examined here. Galactose induced the genes for the Leloir pathway to a higher level compared with lactose; this indicates that these genes are controlled by a different regulator to the tagatose-6-P pathway. The most likely candidate is the LacI-type regulator GalR encoded by CAC2962 since this gene is the last gene in the Leloir pathway operon.

\section{Pentose metabolism}

Numerous genes for the uptake and metabolism of pentose sugars (Rodionov et al. 2001) were induced when cells were grown on xylose or arabinose (Fig. 5). Previous studies have identified genes responsible for arabinose and xylose metabolism via the PPP. Bioinformatic analyses have identified putative CRE sequences, AraR-binding sites and XylR-binding sites (Rodionov et al. 2001). Most of the genes responsible for pentose uptake and metabolism are located in the region of the genome encompassing CAC1339CAC1349. Transcriptional unit predictions made by Paredes et al. (2004) indicate that these genes are in seven transcriptional units as shown in Fig. 5. This region includes genes for two putative arabinose $\left(\mathrm{Na}^{+} / \mathrm{H}^{+}\right)$symporters designated araE1 (CAC1339) and araE2 (CAC1345), which were thought to be responsible for arabinose uptake. Only xylose induced CAC1339, which is located in a monocistronic operon downstream of a putative AraR-binding site and CRE element. Both arabinose and xylose induced a second operon containing araE2 (CAC1345) and a putative arabinose isomerase gene designated araA2 (CAC1346). A possible CRE site was identified upstream of CAC1345; however, no AraR-binding site has been identified. The gene expression pattern and genetic organization strongly suggest that araE2 (CAC1345) encodes the primary arabinose transporter, while the araE1 (CAC1339) product may be responsible for xylose transport.

Two additional transcriptional units in the CAC1339CAC1349 region were strongly induced by both xylose and arabinose. One of these transcriptional units is located downstream of araE2 and araA2, and encompasses CAC1347-CAC1349. This operon contains putative PPP genes encoding a transaldolase (CAC1347), a transketolase (CAC1348) and an epimerase (CAC1349). The second
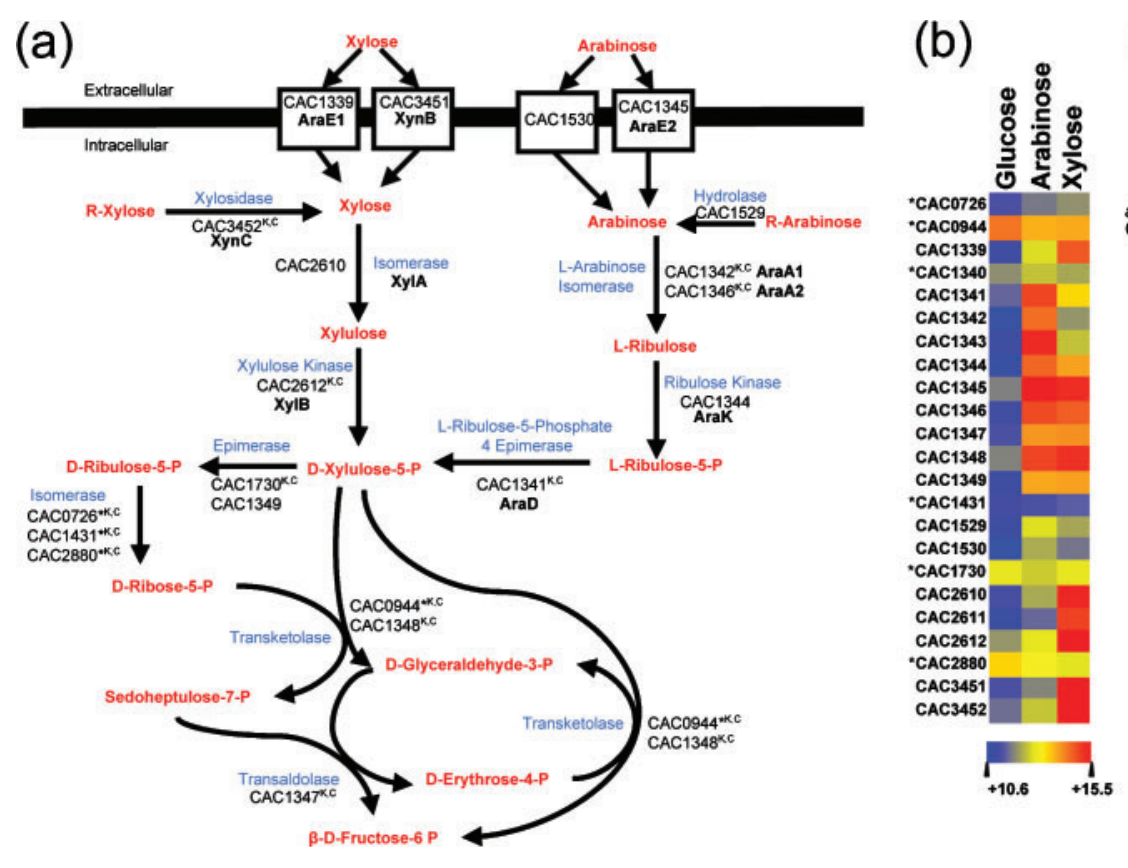

(c)
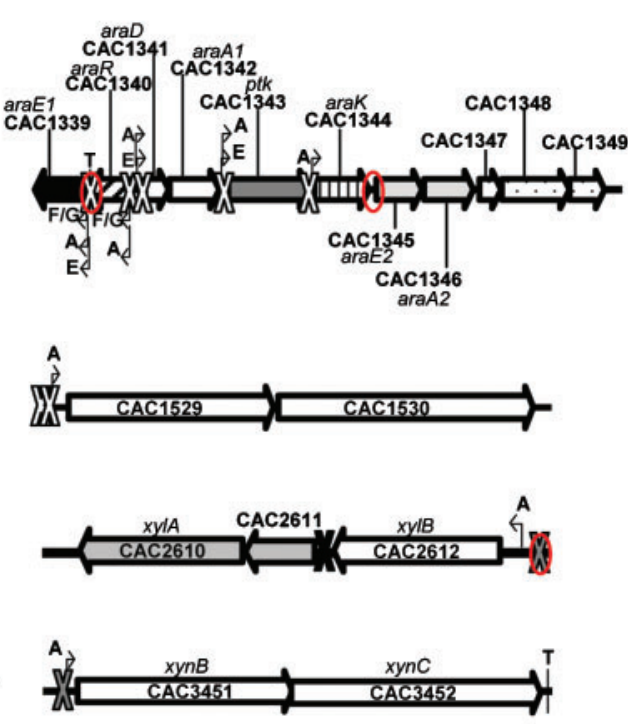

Fig. 5. Differential expression of pentose utilization genes. (a) Schematic of pentose utilization. Genes are annotated as in Fig. 2a. (b) Heat map of $\log _{2}$-transformed expression values of pentose utilization genes during growth on glucose, arabinose and xylose (as described in Fig. 2 legend). (c) Genetic map of arabinose and xylose utilization operons. Xs indicate presumed XyIR- (grey X) and AraA- (white X)-binding sites identified by Rodionov et al. (2001). A possible XylR-binding site identified in this study is indicated by a black X. Potential CRE elements identified by Rodionov et al. (2001) are marked with red ovals. Transcriptional unit predictions made by Paredes et al. (2004) are identified as in Fig. 2c. 
transcriptional unit is a monocistronic operon located upstream of araE2 and araA2 that encodes a putative sugar kinase (araK, CAC1344) and has a potential AraR-binding sequence in the upstream region (Rodionov et al., 2001). The CAC1344 gene product was identified as a putative ribulose kinase (Rodionov et al., 2001); however, it is not recorded as such in the genome annotation, KEGG or BioCyc (Kanehisa et al., 2006; Nölling et al., 2001; Karp et al., 2005).

Three genes in the CAC1339-CAC1349 region were strongly induced by arabinose and only weakly induced by xylose. Two of these genes, CAC1341 and CAC1342, are located in the same operon and appear to encode a ribulose-5-P epimerase ( $a r a D)$ and an arabinose isomerase ( $\operatorname{araA1}$ ), respectively. The third gene, CAC1343, encodes a putative phosphoketolase and is located in a separate monocistronic operon. A previous bioinformatics study identified potential AraR-binding sites upstream of both operons; however, no CRE sequences were found (Rodionov et al., 2001).

Arabinose also induced a bicistronic operon, CAC1529 and CAC1530, which encode a putative glycosyl hydrolase and a symporter, respectively. A BLASTP analysis of the protein sequence derived from CAC1529 indicates that it is similar to COG3940 and may contain $\beta$-xylosidase activity (Altschul et al., 1990; Tatusov et al., 1997). However, the expression data suggest that the CAC1529 gene product may also function as an $\alpha$-arabinosidase, as is common with $\beta$-xylosidases from other organisms (Li et al., 2000). The resulting protein is likely to hydrolyse $\alpha$-arabinosides and/or $\beta$-xylosides located in the cytoplasm, as no export signals were identified using SignalP (Bendtsen et al., 2004). BLASTP analysis of the CAC1530-derived protein sequence indicated that it is similar to LacY-type galactoside permeases; however, gene expression levels were highest during growth on arabinose, suggesting that this permease may transport arabinose or $\alpha$-arabinosides (Altschul et al., 1990). If this is the case, then the combined actions of the two gene products would provide the cell with a mechanism to take up and hydrolyse $\alpha$-arabinosides.

Three operons in other regions of the genome were induced by xylose but not arabinose. One operon included $x y n B$ (CAC3451) and $x y n C$ (CAC3452), which encode a putative xylose symporter and a xylosidase, respectively. The second xylose-induced operon had a single gene, $x y l B$ (CAC2612), which appears to encode a xylulose kinase. Putative XylRbinding sites have been identified by Rodionov et al. (2001) in the upstream regions of these operons. Downstream of $x y l B$, a third operon containing CAC2611 and CAC2610 was also induced by xylose. CAC2611 encodes an unidentified hypothetical protein, and CAC2610 encodes a putative fucose isomerase. A previously unidentified putative XylRbinding site was found to be located upstream of the first gene in the operon. This, along with the location of CAC2610 and expression data, suggests that CAC2610 encodes a xylose isomerase which was not identified by previous studies. Regulation of the xylose-induced operons is likely to be via CCR and/or XylR since potential CRE sequences have been identified upstream of these operons (Rodionov et al., 2001).

Regulation of the PPP is at least partially at the transcriptional level since genes that apparently encode two transketolases, a transaldolase and an epimerase were induced by arabinose or xylose. The genome also includes putative genes for three ribose isomerases, a second epimerase and a third transketolase that were not induced by growth on xylose or arabinose. Potential CRE sequences have been identified, in previous studies, upstream of most of the metabolic operons induced during growth on pentoses, suggesting that CcpA plays a role in the regulation of these genes (Rodionov et al., 2001). Previous studies by Rodionov et al. (2001) identified a putative araR gene (CAC1340), which was not induced in any of the conditions examined in this study. All five of the operons encompassing CAC1339-CAC1344 have putative AraR-binding sites in their promoter regions (Fig. 5) but no AraR-binding sites were identified in the downstream pentose-induced region CAC1345-CAC1349. It should also be noted that the transcriptional units CAC1341-CAC1342 and CAC1343 had the highest expression levels during growth on arabinose, have putative AraR-binding sites, and lack identifiable CRE sequences, suggesting that expression of these operons is not regulated by CcpA and that the primary regulator may be AraR. The putative $x y l R$ gene (CAC3673) was not differentially expressed in any of the conditions that were tested in this study; however, potential XylR-binding sites have been identified upstream of the operons encoding proteins required for xylose metabolism that are not located in the CAC1339-CAC1349 region (Rodionov et al., 2001). Further studies need to be performed to fully elucidate the regulation of pentose metabolism genes in C. acetobutylicum.

\section{Prophage gene expression}

A large number of the differentially regulated genes were part of a chromosomally located $C$. acetobutylicum phi Clo2 prophage (Casjens, 2003; Nölling et al., 2001). Many of the prophage genes were induced by lactose, galactose and maltose compared with the other sugars (Fig. 6). To the best of our knowledge this is the first report of carbohydrate-induced expression of C. acetobutylicum prophage genes and may explain decreased growth rates seen during growth on galactose and lactose ( $\mathrm{Yu}$ et al., 2007; Supplementary Fig. S2).

\section{Conclusions}

The transcriptional profiles of C. acetobutylicum grown on 11 carbohydrate sources were analysed. Genes for multiple types of carbohydrate transporters and metabolic enzymes were differentially expressed, indicating that these processes are highly regulated at the transcriptional level. Transport operon expression patterns suggest that disaccharides and 


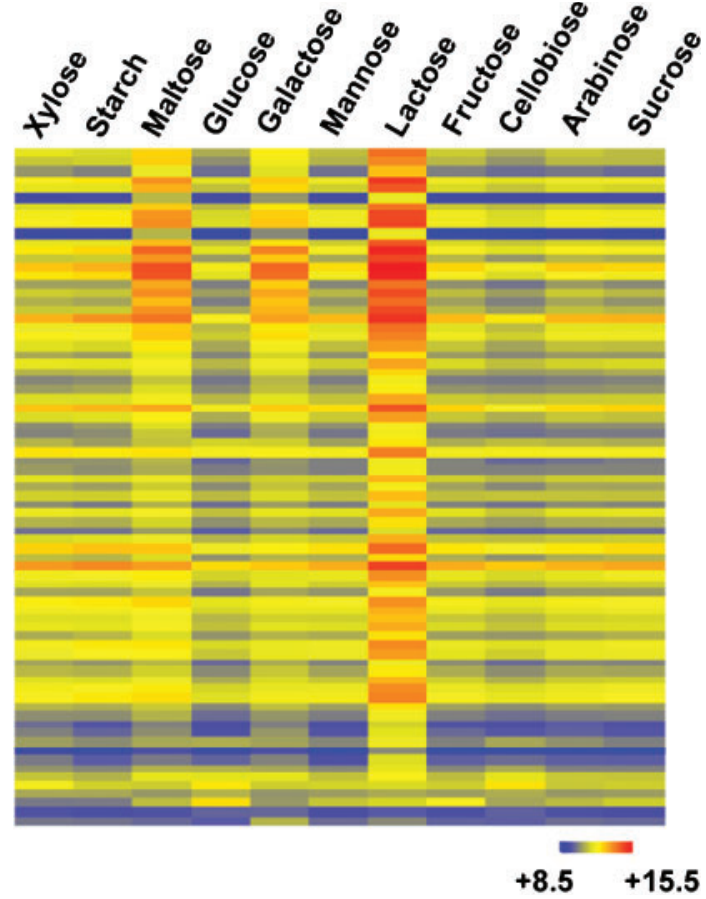

Fig. 6. Prophage expression. Heat map indicating gene expression levels of the phi Clo2 prophage during growth on 11 different sugars. A key indicating the range of $\log _{2}$-transformed expression values is located in the bottom right-hand corner.

hexoses are transported by the PTS family of transporters, while pentoses are transported by sodium or proton symporters.

The occurrence of CCR made it difficult to use only microarray data to confirm transporter genes for preferred sugars, as their expression may not be differentially regulated when cells are grown on less preferred sugars. Further complicating the matter, many PTSs are promiscuous and, therefore, capable of transporting multiple sugars. For example, the EIIAB $^{\text {Man }}$ and EIIAB ${ }^{\text {Glu }}$ PTS components from Streptococcus sp. are capable of participating in the transport of glucose and fructose in addition to mannose (Abranches et al., 2003; Liberman \& Bleiweis, 1984). In these cases we used the genomic context, sequence homology and previous results to assign potential substrates to specific transporters.

The expression levels of many metabolic genes were repressed by growth on glucose, which is consistent with regulation via CCR. Putative CRE sites have been identified, in previous reports, within the promoter regions in some of these inducible loci (Behrens et al., 2001; Rodionov et al., 2001; Tangney et al., 2001; Yu et al., 2007). There are several key proteins encoded by the $C$. acetobutlylicum genome that are likely to be involved in CCR, including HPr (CAC1820), EI (CAC3087), CcpA (CAC3037) and HPrK/P (CAC1089) (Rodionov et al., 2001; Tangney et al., 2003). The CCR mechanism is thought to depend on protein-protein interactions controlled by post-transcriptional protein phosphorylation (Brückner \& Titgemeyer, 2002). This is corroborated by our results, which indicate that the transcriptional levels of the HPr, HPrK/P, CcpA and EI genes do not vary with exposure to the range of sugars tested (data not shown).

The data presented here suggest improvements to genomic annotations for several genes involved in pentose metabolism. Rodionov et al. (2001) identified the CAC2610 gene product as a xylose isomerase. Our data support this prediction, but this gene was identified as a fucose isomerase in KEGG and in the genome annotation. CAC1344 was identified in the genome annotation and KEGG as a xylulose kinase, but the expression data suggest that this gene encodes a ribulose kinase which is required for arabinose metabolism. CAC1349 was annotated as an aldose 1-epimerase, but examination of the expression data and operon structure suggests that it encodes an aldose 3epimerase for the PPP. Previous studies identified CAC1339 as araE1, encoding an arabinose symporter, but the expression data indicate that CAC1339 probably encodes a xylose transporter (Rodionov et al., 2001). These updated annotations provide a more accurate description of pentose uptake and metabolism and should enhance efforts to improve biofuel production from substrates containing these sugars.

C. acetobutylicum, like many bacteria, exhibits adaptable metabolic machinery that is able to handle fluctuating environmental carbohydrate availability. The regulation of these processes is complex and appears to be controlled by both CCR and operon-specific regulators. The data presented here provide an excellent foundation to design studies for elucidating regulatory mechanisms for carbohydrate uptake and metabolism in C. acetobutylicum.

\section{NOTE ADDED IN PROOF}

While this manuscript was in revision, a paper was published (Gu et al., 2010) that characterized the xylose isomerase (CAC2611) and confirmed the XylR-binding site upstream of CAC2610.

\section{REFERENCES}

Abranches, J., Chen, Y. Y. \& Burne, R. A. (2003). Characterization of Streptococcus mutans strains deficient in EIIAB Man of the sugar phosphotransferase system. Appl Environ Microbiol 69, 47604769.

Altschul, S. F., Gish, W., Miller, W., Myers, E. W. \& Lipman, D. J. (1990). Basic local alignment search tool. J Mol Biol 215, 403-410.

Amster-Choder, O. \& Wright, A. (1997). BglG, the response regulator of the Escherichia coli bgl operon, is phosphorylated on a histidine residue. J Bacteriol 179, 5621-5624.

Behrens, S., Mitchell, W. \& Bahl, H. (2001). Molecular analysis of the mannitol operon of Clostridium acetobutylicum encoding a phosphotransferase system and a putative PTS-modulated regulator. Microbiology 147, 75-86. 
Bendtsen, J. D., Nielsen, H., von Heijne, G. \& Brunak, S. (2004). Improved prediction of signal peptides: SignalP 3.0. J Mol Biol 340, 783-795.

Bolstad, B. M., Irizarry, R. A., Astrand, M. \& Speed, T. P. (2003). A comparison of normalization methods for high density oligonucleotide array data based on variance and bias. Bioinformatics 19, 185193.

Brückner, R. \& Titgemeyer, F. (2002). Carbon catabolite repression in bacteria: choice of the carbon source and autoregulatory limitation of sugar utilization. FEMS Microbiol Lett 209, 141-148.

Casjens, S. (2003). Prophages and bacterial genomics: what have we learned so far? Mol Microbiol 49, 277-300.

Deutscher, J., Francke, C. \& Postma, P. W. (2006). How phosphotransferase system-related protein phosphorylation regulates carbohydrate metabolism in bacteria. Microbiol Mol Biol Rev 70, 939-1031.

Ezeji, T. \& Blaschek, H. P. (2008). Fermentation of dried distillers' grains and solubles (DDGS) hydrolysates to solvents and value-added products by solventogenic clostridia. Bioresour Technol 99, 52325242.

Gapes, J. R. (2000). The economics of acetone-butanol fermentation: theoretical and market considerations. J Mol Microbiol Biotechnol 2, $27-32$.

Gu, Y., Ding, Y., Ren, C., Sun, Z., Rodionov, D. A., Zhang, W., Yang, S., Yang, C. \& Jiang, W. (2010). Reconstruction of xylose utilization pathway and regulons in Fermicutes. BMC Genomics 11: 255 (in press). doi:10.1186/1471-2164-11-255

Gutierrez, N. A. \& Maddox, I. S. (1996). Galactose transport in Clostridium acetobutylicum p262. Lett Appl Microbiol 23, 97-100.

Irizarry, R. A., Bolstad, B. M., Collin, F., Cope, L. M., Hobbs, B. \& Speed, T. P. (2003). Summaries of Affymetrix GeneChip probe level data. Nucleic Acids Res 31, e15.

Jones, D. T. \& Woods, D. R. (1986). Acetone-butanol fermentation revisited. Microbiol Rev 50, 484-524.

Kanehisa, M., Goto, S., Hattori, M., Aoki-Kinoshita, K. F., Itoh, M., Kawashima, S., Katayama, T., Araki, M. \& Hirakawa, M. (2006). From genomics to chemical genomics: new developments in KEGG. Nucleic Acids Res 34, D354-D357.

Karp, P. D., Ouzounis, C. A., Moore-Kochlacs, C., Goldovsky, L., Kaipa, P., Ahren, D., Tsoka, S., Darzentas, N., Kunin, V. \& LopezBigas, N. (2005). Expansion of the BioCyc collection of pathway/ genome databases to 160 genomes. Nucleic Acids Res 33, 6083-6089.

Li, Y. K., Yao, H. J. \& Cho, Y. (2000). Effective induction, purification and characterization of Trichoderma koningii G-39 $\beta$-xylosidase with high transferase activity. Biotechnol Appl Biochem 31, 119-125.

Liberman, E. S. \& Bleiweis, A. S. (1984). Transport of glucose and mannose by a common phosphoenolpyruvate-dependent phosphotransferase system in Streptococcus mutans GS5. Infect Immun 43, 1106-1109.

Mitchell, W. J. \& Tangney, M. (2005). Carbohydrate uptake by the phosphotransferase system and other mechanisms. In Handbook on Clostridia, pp. 155-176. Edited by P. Durre. Boca Raton, FL: CRC Press.

Mitchell, W. J., Shaw, J. E. \& Andrews, L. (1991). Properties of the glucose phosphotransferase system of Clostridium acetobutylicum NCIB 8052. Appl Environ Microbiol 57, 2534-2539.

Nölling, J. G., Breton, M. V., Omelchenko, K. S., Makarova, Q., Zeng, R., Gibson, H. M., Lee, J., Dubois, D., Qiu, J. \& other authors (2001). Genome sequence and comparative analysis of the solvent-producing bacterium Clostridium acetobutylicum. J Bacteriol 183, 4823-4838.

Novichkov, P. S., Laikova, O. N., Novichkova, E. S., Gelfand, M. S., Arkin, A. P., Dubchak, I. \& Rodionov, D. A. (2010). RegPrecise: a database of curated genomic inferences of transcriptional regulatory interactions in prokaryotes. Nucleic Acids Res 38, D111-D118.

Paquet, V., Croux, C., Goma, G. \& Soucaille, P. (1991). Purification and characterization of the extracellular alpha-amylase from Clostridium acetobutylicum ATCC 824. Appl Environ Microbiol 57, 212-218.

Paredes, C. J., Rigoutsos, I. \& Papoutsakis, E. T. (2004). Transcriptional organization of the Clostridium acetobutylicum genome. Nucleic Acids Res 32, 1973-1981.

Pfaffl, M. W. (2001). A new mathematical model for relative quantification in real-time RT-PCR. Nucleic Acids Res 29, e45.

Poolman, B., Knol, J., van der Does, C., Henderson, P. J., Liang, W. J., Leblanc, G., Pourcher, T. \& Mus-Veteau, I. (1996). Cation and sugar selectivity determinants in a novel family of transport proteins. Mol Microbiol 19, 911-922.

Qureshi, N., Li, X. L., Hughes, S., Saha, B. C. \& Cotta, M. A. (2006). Butanol production from corn fiber xylan using Clostridium acetobutylicum. Biotechnol Prog 22, 673-680.

Reid, S. J. (2005). Genetic organization and regulation of hexose and pentose utilization in the clostridia. Handbook on Clostridia, pp. 133153. Edited by P. Durre. Boca Raton, FL: CRC Press.

Reid, S. J., Rafudeen, M. S. \& Leat, N. G. (1999). The genes controlling sucrose utilization in Clostridium beijerinckii NCIMB 8052 constitute an operon. Microbiology 145, 1461-1472.

Rodionov, D. A., Mironov, A. A. \& Gelfand, M. S. (2001). Transcriptional regulation of pentose utilisation systems in the Bacillus/Clostridium group of bacteria. FEMS Microbiol Lett 205, 305314.

Rosen, S. \& Skaletsky, H. J. (2000). Primer3 on the WWW for general users and for biologist programmers. In Bioinformatics Methods and Protocols: Methods in Molecular Biology, pp. 365-386. Edited by S. Krawetz \& S. Misener. Totowa, NJ: Humana Press.

Ryttersgaard, C., Le Nours, J., Lo Leggio, L., Jørgensen, C. T., Christensen, L. L., Bjørnvad, M. \& Larsen, S. (2004) The structure of endo-beta-1,4-galactanase from Bacillus licheniformis in complex with two oligosaccharide products. J Mol Biol 341, 107-117.

Saier, M. H., Jr \& Reizer, J. (1992). Proposed uniform nomenclature for the proteins and protein domains of the bacterial phosphoenolpyruvate:sugar phosphotransferase system. J Bacteriol 174, 14331438.

Saier, M. H., Jr, Chauvaux, S., Cook, G. M., Deutscher, J., Paulsen, I. T., Reizer, J. \& Ye, J. J. (1996). Catabolite repression and inducer control in Gram-positive bacteria. Microbiology 142, 217-230.

Saurin, W. \& Dassa, E. (1994). Sequence relationships between integral inner-membrane proteins of binding protein-dependent transport systems: evolution by recurrent gene duplications. Protein Sci 3, 325-344.

Singh, K. D., Schmalisch, M. H., Stülke, J. \& Görke, B. (2008). Carbon catabolite repression in Bacillus subtilis: quantitative analysis of repression exerted by different carbon sources. J Bacteriol 190, $7275-7284$.

Smyth, G. K. (2004). Linear models and empirical Bayes methods for assessing differential expression in microarray experiments. Stat Appl Genet Mol Biol 3, Article 3. doi:10.2202/1544-6115.1027

Sutrina, S. L., Reddy, P., Saier, M. H., Jr \& Reizer, J. (1990). The glucose permease of Bacillus subtilis is a single polypeptide chain that functions to energize the sucrose permease. J Biol Chem 265, 1858118589.

Tam, R. \& Saier, M. H., Jr (1993). Structural, functional, and evolutionary relationships among extracellular solute-binding receptors of bacteria. Microbiol Rev 57, 320-346. 
Tangney, M. \& Mitchell, W. J. (2000). Analysis of a catabolic operon for sucrose transport and metabolism in Clostridium acetobutylicum ATCC 824. J Mol Microbiol Biotechnol 2, 71-80.

Tangney, M. \& Mitchell, W. J. (2007). Characterisation of a glucose phosphotransferase system in Clostridium acetobutylicum ATCC 824. Appl Microbiol Biotechnol 74, 398-405.

Tangney, M., Brehm, J. K., Minton, N. P. \& Mitchell, W. J. (1998a). A gene system for glucitol transport and metabolism in Clostridium beijerinckii NCIMB 8052. Appl Environ Microbiol 64, 1612-1619.

Tangney, M., Rousse, C., Yazdanian, M. \& Mitchell, W. J. (1998b). Note: sucrose transport and metabolism in Clostridium beijerinckii NCIMB 8052. J Appl Microbiol 84, 914-919.

Tangney, M., Winters, G. T. \& Mitchell, W. J. (2001). Characterization of a maltose transport system in Clostridium acetobutylicum ATCC 824. J Ind Microbiol Biotechnol 27, 298-306.

Tangney, M., Galinier, A., Deutscher, J. \& Mitchell, W. J. (2003). Analysis of the elements of catabolite repression in
Clostridium acetobutylicum ATCC 824. J Mol Microbiol Biotechnol 6, 6-11.

Tatusov, R. L., Koonin, E. V. \& Lipman, D. J. (1997). A genomic perspective on protein families. Science 278, 631-637.

Thompson, J., Hess, S. \& Pikis, A. (2004). Genes malh and pagl of Clostridium acetobutylicum ATCC 824 encode $\mathrm{NAD}^{+}$- and $\mathrm{Mn}^{2+}$-dependent phospho- $\alpha$-glucosidase(s). J Biol Chem 279, 15531561.

Wiesenborn, D. P., Rudolph, F. B. \& Papoutsakis, E. T. (1988). Thiolase from Clostridium acetobutylicum ATCC 824 and its role in the synthesis of acids and solvents. Appl Environ Microbiol 54, 2717-2722.

Yu, Y., Tangney, M., Aass, H. C. \& Mitchell, W. J. (2007). Analysis of the mechanism and regulation of lactose transport and metabolism in Clostridium acetobutylicum ATCC 824. Appl Environ Microbiol 73, 18421850.

Edited by: W. H. Schwarz 